\title{
Online sexual activities in Hispanic women: A chance for non-heterosexual women?
}

\author{
Cristina Giménez-García ${ }^{1}$, Estefanía Ruiz-Palomino ${ }^{1}$, María Dolores Gil-Llario ${ }^{2}$ and \\ Rafael Ballester-Arnal ${ }^{1}$
}

${ }^{1}$ Universidad Jaume I, Castellón de la Plana, España

${ }^{2}$ Universidad de Valencia, Valencia, España

\begin{abstract}
Sexuality is still modulated by social determinants that promote a passive role for women. In the recent decades, some findings have supported the influence of the Internet on sexuality. However, the relevance of online sexual activities for some groups such as Hispanic young women is still unknown. In this context, this study examines online sexual experience among 310 Hispanic women from Argentina, Mexico and Spain; as well as the role of their offline sexuality and country in this sexual pattern. As a result, Hispanic women report a variety of online sexual activities that ranges from searching information to masturbation. In particular, the Internet use for sexual purposes is more common for homosexual and bisexual women. Therefore, the Internet may be a new context to explore sexuality for Hispanic women, particularly for those who self-identified as lesbians and bisexuals.
\end{abstract}

Keywords: Online sexual activities; Hispanic culture; young people; women; sexual orientation.

Actividades sexuales online en mujeres hispanas: ¿Una oportunidad para mujeres no heterosexuales?

Resumen: La sexualidad todavía está modulada por determinantes sociales que favorecen un rol pasivo entre las mujeres. Desde hace algunas décadas, algunos hallazgos han apoyado la influencia de internet en la sexualidad. Sin embargo, la importancia de las actividades sexuales online para algunos grupos como las mujeres jóvenes hispanas todavía es desconocida. En este contexto, este estudio examina la experiencia sexual online entre 310 mujeres hispanas de Argentina, México y España, así como el rol de la sexualidad offline y su procedencia en este patrón de conducta. Como resultado, las mujeres hispanas reportan variedad de conductas sexuales online que abarcan desde la búsqueda de información hasta la masturbación. En particular, el uso de internet con propósitos sexuales es más común entre las mujeres homosexuales y bisexuales. Así pues, internet podría suponer un nuevo contexto para explorar la sexualidad entre las mujeres hispanas, en particular, para aquellas que se identifican con la homosexualidad y la bisexualidad.

Palabras clave: Actividades sexuales online; cultura hispana; juventud; mujeres; orientación sexual.

\section{Introduction}

Currently, the Internet plays an essential role in lifestyle. Regarding sexuality, several studies affirm a major presence of online sexual activities among young

Recibido: 26 de agosto 2019; aceptado: 10 de octubre 2019 Corresponding author: Cristina Giménez-García, Facultad de Psicología, Universidad Jaume I, Avda Vicent Sos Baynat, s/n. 12071 Castellón, España. E-mail: gimenezc@uji.es people, ranging from searching for information about sexuality to purchasing sexual toys, as well as using online pornography or meeting partners for sexual or romantic purposes (Ballester-Arnal, Castro-Calvo, Gil-Llario, \& Gil-Julia, 2016; Daneback, Cooper, \& Mansson, 2005; Döring, 2009; Döring, Daneback, Shaughnessy, Grov, \& Byers, 2017).

In this context, women have reported fewer online sexual activities than men, in particular, for those oriented to sexual arousal options such as cybersex (Ballester- 
Arnal, Castro-Calvo, Gil-Llario, \& Giménez-García, 2014; Shaugnessy, Byers, \& Walsh, 2011; Weinstein, Zolek, Babkin, Cohen, \& Lejoyeux, 2015). At the same time, women have revealed some perceived benefits, such as improving their confidence to talk to partner, as well as an increase about their quantity and quality of sexual relationships (Grov, Gillespie, Royce, \& Lever, 2011; Tripodi et al., 2015). In any case, some studies have also revealed a riskier profile among young women based on aspects such as time spent and emotional regulation on account of cybersex activity (Ballester-Arnal, Gil-Llario, Giménez-García, Castro-Calvo, \& Cárdenas-López, 2017; Giménez-García, Ballester-Arnal, Gil-Llario, CárdenasLópez, \& Duran-Baca, 2013).

Different variables would underlie online sexual activities. For example, offline sexual frequency and variety would increase online sexual activities among young people (Ballester-Arnal et al., 2016). In particular, offline use of pornography would be associated with cybersex consumption (Snagowski, Laier, Duka, \& Brand, 2016). In addition, the relationship status and its quality would moderate cybersex consumption. That is, single young people and those who reveal more problems in their offline romantic relationships use the Internet for sexual purposes more frequently (Li \& Zheng, 2017). Regarding sexual orientation, young people self-identified as non-heterosexual report more online sexual activities (Daneback, Cooper, \& Månsson, 2005; Shaughnessy, Byers, Clowater, \& Kalinowsky, 2014). In line with DeHaan, Kuper, Magee, Bigelow and Munstanski (2013), these young people would access more inclusive sexual health resources and LGTB + models by using Internet, in order to cover the lack of non-heterosexual referents in their social and physical interactions. In addition, other aspects such as religiosity and social values may influence online sexual activities. Velezmoro, Negy and Livia (2012) found that Peruvian young people, socialised in a more traditional culture, reported more online sexual activities than North American young people, as the latter belonged to a more open-minded society. This may be explained as a strategy to balance some social restrictions in Catholic and gendered societies where some aspects of sexuality are still taboo.

Regarding young women, there is not enough data about their online sexual experience. In line with Ferree (2003), this analysis would be relevant to comprehend online sexual activities in detail and in particular, when social traditions maintain taboos about sexuality and gender inequality as occurs in Hispanic culture (BallesterArnal et al., 2017; Giménez-García et al., 2013).

In any case, Hispanic women do not make up a homogeneous group and differences in terms of sexual orientation have been revealed (Deardorff, Tschann, \& Flores, 2008; Gil-Llario, Giménez-García, BallesterArnal, Cárdenas-López, \& Durán-Baca, 2017), as well as sexual attitudes (Ilabaca, Fuertes, \& Orgaz, 2015) or sexual health behaviours based on gender inequality (Giménez-García et al., 2013).

For these reasons, this study analyses the online sexual experience in Hispanic women from different countries (Mexico, Spain and Argentina). All of them share traditional values, such as marianismo (i.e., women as submissive to men) and machismo (i.e., men as autonomous and authoritarian) (Cianelli \& Villegas, 2016), but not gender inequality as past literature has reported (Ballester et al., 2017; Gil-Llario et al., 2017). In particular, following the Gender Inequality Index (United Nations Development Programme, 2015), Spain shows a more equal position $\left(15^{\circ}\right.$ position over 165$)$ than Mexico $\left(73^{\circ}\right.$ position over 165$)$ and Argentina $\left(77^{\circ}\right.$ position over 165).

Secondly, the study evaluates if offline sexual experience (sexual frequency, pornography use, relationship status and same-sex) and country play some role in online sexual experience (searching for information, sexual chat, isolated and social sexual behaviour) and in problematic cybersex use among women from Argentina, Mexico and Spain.

\section{Method}

\section{Participants}

Three hundred and ten women participated in this study: $32.6 \%$ from Spain $(n=101), 35.2 \%$ from Argentina $(n=109)$ and $32.3 \%$ from Mexico $(n=100)$. Regarding age, the mean age for Spanish women was $20.88(S D=1.45)$, mean age for Argentinian women was $20.70(S D=1.78)$ and the mean age for Mexican women was $20.31(S D=2.21)$. There were no statistically significant differences based on age $(F=2.54 ; p \leq$. 080). All participants lived in urban areas and were college students in their countries. All of them had access to the Internet and there were no statistically significant differences in weekly use $(F=0.23 ; p \leq$. 797): The Spanish mean use was 9.36 hours $(S D=12.49)$, the Argentinian mean use was 9.66 hours $(S D=10.81)$ and the Mexican mean use was 8.45 hours $(S D=11.36)$.

\section{Instruments}

Background questionnaire. This short questionnaire explores socio-demographic variables (age, gender, relationship status and level of studies), Internet use 
(computer access and hours spent online in the last week) and general sexual aspects, such as having sexual experience, frequency of sexual intercourse (monthly, weekly or annually), sexual orientation, same-sex behaviour and offline pornography consumption.

Internet Sex Screening Test (ISST, Delmonico, 1997; Spanish version by Ballester, Gil, Gómez, \& Gil, 2010). This 25-item true-false questionnaire explores online sexual behaviour through five dimensions (Delmonico \& Miller, 2003): (1) online sexual compulsivity is related to sexual problems and lack of control; (2) online sexual behaviour-social is based on social interaction such as sexual chats; (3) online sexual behaviour-isolation non compulsive is related to isolated forms of cybersex; (4) online sexual spending describes monetary investment during online sex behaviour, and (5) perceived seriousness of online sexual behaviour which is based on selfperception of their own behaviour. In addition, this test allows us to identify safe and risky consumption patterns (Carnes, Delmonico, \& Griffin, 2007): (a) recreational users without foreseeable negative effects (scores ranging from 0 to 8); (b) risk users who use cybersex excessively (scores ranging from 9 to 18), and (c) pathological users who would use cybersex impulsively and feeling out of control (scores ranging from 19 to 25). The Spanish validation, as well as the original version, has 25 truefalse items to measure them. Its internal consistency was 0.88 and its cybertest-retest reliability was 0.84 . For this study, the internal consistency was 0.79 .

\section{Procedure}

The study was disseminated in outreach activities for promoting healthy lifestyles carried out in university campuses. Interested participants received more information about the study in the laboratories and, after their informed consent was given, they self-completed the questionnaires. The task of answering the questionnaire items took 30 minutes and it was voluntary, confidential and anonymous. Previously, all institutions involved, and their Ethical Committees had approved the study.

\section{Statistical analyses}

Firstly, in order to examine differences in online sexual experience among Argentinian, Mexican and Spanish women, we carried out Chi ${ }^{2}$ test and Cramer's $V$, as well as Analysis of Variance, Partial eta-squared and Games-Howell post-hoc for the ISST dimensions. Secondly, we carried out a linear regression to evaluate the role of offline sexual experience and country in online sexual experience.

\section{Results} Offline sexual experience in young women from
Argentina, Mexico and Spain.

Most of these young women had sexual experience. Particularly Spanish women (92.9\% of them) who exceed Argentinian (81.7\% of them) and Mexican women $(67 \%$ of them $)\left(C h i^{2}=15.31 ; p \leq\right.$. 001). Regarding frequency of sexual intercourse, more Spanish and Argentinian women reported weekly experience $(75.6 \%$ and $70.9 \%$ respectively) while Mexican women reported monthly practice $(45.5 \%$ of them). These differences were statistically significant $\left(C h i^{2}=38.07 ; p \leq\right.$. 001). In addition, in relation to pornography consumption, there were significant statistical differences $\left(C h i^{2}=6.19 ; p \leq .045\right): 20.2 \%$ of Mexican women consumed it, followed by $13.6 \%$ of Spanish and 5.5\% of Argentinian women.

Regarding being in a relationship more than fifty percent of women, in these three groups, had a steady partner (61.4\% of Spanish women, 50.9\% of Argentinian women and $57.1 \%$ of Mexican women) and differences between being or not in a relationship have not revealed any statistically significant differences $\left(C h i^{2}=1.13 ; p \leq\right.$. 566).

Concerning sexual orientation, most of them selfidentified as heterosexual $(97.7 \%$ of Spanish women, $100 \%$ of Argentinian women and $84.7 \%$ of Mexican women) and a lower percentage as homosexual (2.3\% of Spanish women and $1 \%$ of Mexican women) or bisexual in the case of Mexican women (14.3\%). Significant statistical differences were found in sexual orientation $\left(C h i^{2}=16.49 ; p \leq .002\right)$ but not in same-sex experience $\left(C h i^{2}=5.28 ; p \leq\right.$. 071). In this sense, $11.2 \%$ of Mexican women reported it, followed by $4.5 \%$ of Spanish and $1.8 \%$ of Argentinian women.

\section{Online sexual experience in young women from Argentina, Mexico and Spain.}

Regarding online sexual experience (see Table 1), women from Argentina, Mexico and Spain reveal some differences in searching for sexual information, being involved in sexual chats and using the Internet for masturbation. In these practices, Mexican women exceed Spanish and Argentinian women. The latter group revealed the lowest percentages for all these behaviours. However, a lower percentage of Spanish women reported that nobody knows the sexual use of their computer compared to Argentinian and Mexican 
Table 1. Differences in online sexual experience among Argentinian, Mexican and Spanish women.

\begin{tabular}{|c|c|c|c|c|c|}
\hline Item & $\begin{array}{c}\text { Spanish } \\
\text { women } \\
\%\end{array}$ & $\begin{array}{c}\text { Argentinian } \\
\text { women } \\
\%\end{array}$ & $\begin{array}{c}\text { Mexican } \\
\text { women } \\
\%\end{array}$ & $\operatorname{Chi}^{2}(p)$ & $\begin{array}{l}\text { Cramer' } \\
\quad \mathrm{V}\end{array}$ \\
\hline 1. I have some sexual sites bookmarked. & 6.9 & 0.9 & 10 & $8.21(.016)$ & .163 \\
\hline $\begin{array}{l}\text { 2. I spend more than } 5 \text { hours per week using my computer for sexual } \\
\text { pursuits. }\end{array}$ & 0 & 0 & 1 & $2.11(.349)$ & .082 \\
\hline 3. I have joined sexual sites to gain access to online sexual material. & 0 & 0 & 3 & $6.36(.042)$ & .143 \\
\hline 4. I have purchased sexual products online. & 2 & 0 & 1 & $2.14(.342)$ & .083 \\
\hline 5. I have searched for sexual material through an Internet search tool. & 8.9 & 4.6 & 20 & $13.33(.001)$ & .207 \\
\hline 6. I have spent more money for online sexual material than I planned. & 0 & 0 & 0 & - & - \\
\hline 7. Internet sex has sometimes interfered with my life. & 3 & 0 & 1 & $3.72(.155)$ & .110 \\
\hline 8. I have participated in sexually related chats. & 5 & 4.6 & 14 & $8.10(.017)$ & .162 \\
\hline 9. I have a sexualized username or nickname. & 22.8 & 6.4 & 31 & $20.84(.000)$ & .259 \\
\hline 10. I have masturbated while on the Internet. & 4 & 0.9 & 13 & $14.85(.001)$ & .219 \\
\hline $\begin{array}{l}\text { 11. I have accessed sexual sites from other computers besides my } \\
\text { home. }\end{array}$ & 2 & 0 & 1 & $2.14(.342)$ & .083 \\
\hline 12. No one knows I use my computer for sexual purposes. & 3 & 3.7 & 13 & $10.53(.005)$ & .184 \\
\hline $\begin{array}{l}\text { 13. I have tried to hide what is on my computer or monitor so others } \\
\text { cannot see it. }\end{array}$ & 7.9 & 3.7 & 12 & $5.07(.079)$ & .128 \\
\hline 14. I have stayed up after midnight to access sexual material online. & 1 & 0.9 & 5 & $5.03(.081)$ & .127 \\
\hline 15. I use the Internet to experiment with different aspects of sexuality. & 2 & 0.9 & 5 & $3.67(.159)$ & .109 \\
\hline 16. I have my own website which contains some sexual material. & 1 & 0.9 & 0 & $.96(.618)$ & .056 \\
\hline $\begin{array}{l}\text { 17. I have made promises to myself to stop using the Internet for sexual } \\
\text { purposes. }\end{array}$ & 3 & 0 & 4 & $4.16(.125)$ & .116 \\
\hline 18. I sometimes use cybersex as a reward for accomplishing something. & 2 & 0 & 1 & $2.14(.342)$ & .083 \\
\hline $\begin{array}{l}\text { 19. When I am unable to access sexual information online, I feel } \\
\text { anxious, angry, or disappointed. }\end{array}$ & 3 & 0 & 1 & $3.72(.155)$ & .110 \\
\hline 20. I have increased the risks I take online. & 1 & 1.8 & 8 & $8.65(.013)$ & .167 \\
\hline 21. I have punished myself when I use the Internet for sexual purposes. & 2 & 0 & 0 & $4.14(.126)$ & .116 \\
\hline $\begin{array}{l}\text { 22. I have met face to face with someone I met online for romantic } \\
\text { purposes. }\end{array}$ & 5.9 & 6.4 & 8 & $.370(.831)$ & .035 \\
\hline 23. I use sexual humor and innuendo with others while online. & 8.9 & 6.4 & 16 & $5.49(.064)$ & .133 \\
\hline 24. I have run across illegal sexual material while on the Internet. & 7.9 & 11.9 & 18 & $4.70(.095)$ & .123 \\
\hline 25. I believe I am an Internet sex addict. & 0 & 0 & 0 & - & - \\
\hline
\end{tabular}

women. In any case, these three groups have also reported similar experience in activities such as trying to hide their online sexual experience, as well as using internet for exploring their sexuality.

Regarding unsafe behaviour, there are also differences. Mexican women revealed higher percentage of taking risks such as coming across illegal material or increasing online risks. For the online increased risk category, there are statistically significant differences and, for both of these categories, Spanish women reported the lowest percentages. In general, Cramer's $V$ values are small for these differences.

Concerning subscales of ISST (see table 2), there were statistically significant differences by ANOVA for online sexual behaviour-social, online sexual behaviourisolation non-compulsive and perceived seriousness of online sexual behaviour. In general, the effect sizes were low, although, based on Games-Howell analyses, Mexican participants exceeded Argentinian participants in all these subscales, as well as exceeding Spanish 
Table 2. Differences in dimension of online sexual experience among Argentinian, Mexican and Spanish women.

\begin{tabular}{lcccccc}
\hline \multicolumn{1}{c}{ Dimensions } & $\begin{array}{c}\text { Spanish } \\
\text { women }\end{array}$ & $\begin{array}{c}\text { Argentinian } \\
\text { women }\end{array}$ & $\begin{array}{c}\text { Mexican } \\
\text { women }\end{array}$ & $F(p)$ & $\eta^{2}$ & Games-Howell \\
\hline & \multicolumn{7}{c}{ Mean $(S D)$} \\
\hline Online sexual compulsivity & 0.10 & 0.01 & 0.09 & 1.76 & .011 & \\
(Score:0 to 8) & $(0.51)$ & $(0.19)$ & $(0.35)$ & $(.172)$ & & \\
Online Sexual Behavior - Isolated & 0.30 & 0.11 & 0.61 & 10.63 & .065 & Mexico > Argentina \\
(Score:0 to 6) & $(0.77)$ & $(0.41)$ & $(1.06)$ & $(.000)$ & & Mexico > Spain, \\
Online Sexual Behavior - Social & 0.51 & 0.37 & 0.95 & 9.19 & .057 & Argentina \\
(Score:0 to 6) & $(0.89)$ & $(0.90)$ & $(1.19)$ & $(.000)$ & & \\
Online Sexual Spending & 0.01 & 0 & 0.04 & 1.64 & .011 & \\
(Score:0 to 2) & $(0.14)$ & $0.24)$ & $(.195)$ & & Mexico > Argentina \\
Perceived severity & 0.07 & 0.03 & 0.17 & 3.81 & .024 & Mexico > Spain, \\
(Score:0 to 3) & $(0.39)$ & $(0.18)$ & $(0.45)$ & $(.023)$ & & Argentina \\
ISST & 1.02 & 0.54 & 1.87 & 12.01 & .007 & $(.000)$ \\
(Score:0 to 25) & $(1.99)$ & $(1.31)$ & $(2.50)$ & $(.000)$ & & \\
\hline
\end{tabular}

Note. ANOVA $(F)$, p-value $(p)$, eta squared $\left(\eta^{2}\right)$

participants in online social behaviour. Additionally, there were statistical differences in the global score of ISST. Mexican women revealed a higher total score than Spanish and Argentinian women although the effect size is low.

Regarding the profile of cybersex use, there were no statistically significant differences among these groups of women $\left(C h i^{2}=3.11 ; p \leq .211\right)$. Most of them reported a recreational use. All Argentinian women revealed this type of profile while 3\% of Mexican and 2\% of Spanish women also showed to be risk users.

\section{Influence of offline sexual experience and country on online sexual experience.}

According to the linear regression analysis (see table 3), the most important predictors for online sexual experience were not being heterosexual as well as offline use of pornography. These variables would explain 54\% of the variance for these women from Spain, Argentina and Mexico. However, sexual frequency, relationship status and same sex have not shown any link to online sexual experience.

Table 3. Linear regression analysis for online sexual experience.

\begin{tabular}{lcccccc}
\hline \multicolumn{1}{c}{ Variable } & $B$ & $e$ & \multicolumn{2}{c}{$I C$} & $R^{2}$ & $F(p)$ \\
\hline Heterosexuality & -1.00 & .097 & -1.19 & -0.80 & & 57.81 \\
Porno & 0.11 & 0.34 & 0.04 & 0.17 & & $(.001)$ \\
\hline
\end{tabular}

Note. Beta $(B)$, error $(e)$, interval confidence $(I C), \mathrm{r}$ square $\left(R^{2}\right)$, ANOVA $(F)$, p-value $(p)$

\section{Discussion}

This study evaluated the sexuality of Hispanic young women on the Internet. This context may promote an improvement of their sexual life, as well as an increase of some sexual risk behaviours and damaging consequences (Ferree, 2003). In general, as past studies supported (Ballester et al., 2016; Döring et al., 2017), our findings have revealed a recreational use of online sexual activities among Argentinian, Mexican and Spanish women. In particular, these Hispanic women have shown a variety of sexual practices on the Internet to experiment their sexuality, in relation to searching for information but also in relation to masturbation or being involved in sexual chats. In line with Daneback et al. (2007), these online sexual activities may also modulate their offline sexuality, as some of them report meeting face-to-face online contacts for romantic purposes.

Regarding problematic use, a lower percentage of women have shown a riskier use of the Internet for sexual purposes. In line with past studies (Ballester et al., 2017), these women have reported practices such as coming across illegal material or taking risks more frequently. In general, their prevalence of online sexual experience is lower than what previous studies showed for women from Canada or Sweden (Tripodi et al., 2015; Shaughnessy et al., 2014). This difference may connect to their more open-minded attitudes towards sexuality. According to Social Structural Theory, unequal social and cultural contexts may have an influence on women's sexuality (Schmitt and the International Sexuality Description Project, 2004). Therefore, women who live 
in contexts with more equality would report more sexual experience than those who live in unequal societies.

Following from our findings, online sexual activities seem to be more frequent for those women who selfidentified as non-heterosexual and use more pornography in offline contexts. As past studies supported, the anonymity of and possibilities offered by the Internet would become a resource to find convenient information, meeting like-minded persons, as well as experiencing their sexuality without restrictions (Döring, 2009). This would be more noticeable in social contexts with Hispanic and Catholic traditions, where sexuality is still a taboo. In this sense, lesbian and bisexual women would have more difficulties in expressing their offline sexuality and the Internet would balance some sexual needs and improve their quality of life. In line with other researchers (Snagowski et al., 2016), some practices such as an offline use of pornography has also been linked to online sexual activities in these Hispanic young women.

These findings should be considered in the light of some limitations. Future studies should include a greater variety of Latin countries, in order to generalize these results. In this sense, developing comparisons among different societies based on their gender inequality would also be relevant. In addition, with greater sexual diversity in the participants, our findings would be more strongly supported.

The Internet seems to be a context where Hispanic women also develop their sexuality, as Ballester-Arnal et al. (2017) reported. This would be particularly more relevant for those women who have more difficulties to express their sexuality as lesbians and bisexuals. As our findings support, even their prevalence is less than in other countries with more open-minded views on sexuality, Hispanic women have revealed a broader variety of online sexual activities. Therefore, women's sexuality in Catholic traditions may be more complex and varied than various traditions have supported. The Internet may represent for them a setting to improve their sexual health and identity. Therefore, we should develop more online sexual interventions to cover their needs and to reverse the damaging influence of some cultures on women's sexuality.

\section{Conflicts of interest}

The authors have no conflicts of interest to declare.

\section{References}

Alcalde, M. \& Quelopana, A. M. (2013). Latin American immigrant women and intergenerational sex education. Sex education: Sexuality, Society and Learning 13(3), 291-304.
Ballester-Arnal, R., Castro-Calvo, J., Gil-Llario, M. D., \& GilJulia, B. (2016). Cybersex addiction: a study on Spanish college students. Journal of Sex and Marital Therapy, 43(6), 567-585.

Ballester-Arnal, R., Castro-Calvo, J., Gil-Llario, M. D., \& Giménez-García, C. (2014). Relationship status as an influence on cybersex activity: Cybersex, youth and the steady partner. Journal of Sex \& Marital Therapy, 40(5), 444456.

Ballester-Arnal, R., Gil-Llario, M. D., Giménez-García, C., Castro-Calvo, J., \& Cárdenas-López, G. (2017). Sexuality in the internet era: expressions of Hispanic adolescent and young people. Sexual addiction \& Compulsivity, 3(24), 140-155.

Ballester, R., Gil, M. D., Gómez. S., \& Gil, B. (2010). Propiedades psicométricas de un instrumento de evaluación de la adicción al cibersexo [Psychometric properties of an instrument for assessing cybersex addiction]. Psicothema, 22(4), 1048-1053.

Ballester-Arnal, R., Giménez-García, C., Gil-Llario, M. D., \& Castro-Calvo, J. (2016). Cybersex in the "Net generation": Online sexual activities among Spanish adolescents. Computers in Human Behavior, 57, 261-266.

Carnes, P., Delmonico, D. L., \& Griffin, E. (2007). In the shadows of the net. Minnesota: Hazelden.

Cianelli, R. \& Villegas, N. (2016). Social determinants of health for HIV among Hispanic women. Hispanic Health Care International, 14(1), 4-9.

Daneback, K., Cooper, A., \& Månsson, S. (2005). An Internet Study of Cybersex Participants. Archives of Sexual Behavior, 34(3), 321-328.

Daneback, K., Månsson, S. A., \& Ross, M. W. (2007). Using the Internet to find offline sex partners. Cyber psychology \& Behavior, 10(1), 100-107.

DeHaan, S., Kuper, L. E., Magee, J. C., Bigelow, L., \& Mustanski, B. S. (2013). The Interplay between Online and Offline Explorations of Identity, Relationships, and Sex: A MixedMethods Study with LGBT Youth. The Journal of Sex Research, 50(5), 421-434.

Delmonico, D. L. (1997). Internet Sex Screening Test. Retrieved May 15, 2003, from http://www.sexhelp.com

Delmonico, D. L. \& Miller, J. (2003). The Internet Sex Screening Test: a comparison of sexual compulsives versus non-sexual compulsives. Sexual and Relationship Therapy, 18(3), 261276.

Döring, N. (2009). The Internet's impact on sexuality: A critical review of 15 years of research. Computers in Human Behavior, 25, 1089-1101.

Döring, N., Daneback, K., Shaughnessy, K., Grov, C., \& Byers, E. S. (2017). Online Sexual Activity Experiences Among College Students: A four country comparison. Archives of Sexual Behavior, 46(6), 1641-1652.

Ferree, M. C. (2003). Women and the web: cybersex activity and implications. Sexual and Relationship Therapy, 18(3), 385393.

Giménez-García, C., Ballester-Arnal, R., Gil-Llario, M. D., Cárdenas-López, G., \& Duran-Baca, X. (2013). Culture as an Influence on the Perceived Risk of HIV Infection: A Differential Analysis Comparing Young People from Mexico and Spain. Journal of Community Health, 38(3), 434-442. 
Gil-Llario, M. D., Giménez-García, C., Ballester-Arnal, R., Cárdenas-López, G., \& Durán-Baca, X. (2017). Gender, Sexuality, and Relationships in Young Hispanic People. Journal of Sex and Marital Therapy, 43(5), 456-462.

Grov, C., Gillespie, B. J., Royce, T., \& Lever, J. (2011). Perceived consequences of casual online sexual activities on heterosexual relationships: a US online survey. Archives of Sexual Behavior, 40(2), 429-439.

Li, D. \& Zheng, L. (2017). Relationship quality predicts online sexual activities among Chinese heterosexual men and women in committed relationships. Computers in Human Behavior, 70, 244-250.

Schmitt D. P. \& the International Sexuality Description Project. (2004). Patterns and universals of adult romantic attachment across 62 cultural regions: Are models of self and of other pancultural constructs? Journal of Cross-Cultural Psychology, 35(4), 367-402.

Shaughnessy, K., Byers, E. S., Clowater, S. L., \& Kalinowsky, A. (2014). Self-appraisals of arousal-oriented online sexual activities in University and Community Samples. Archives of Sexual Behavior, 43(6), 1187-1197.

Shaugnessy, K., Byers, E. S., \& Walsh, L. (2011). Online Sexual Activity experience of heterosexual students: gender similarities and differences. Archives of Sexual Behavior, 40(2), 419-427.

Snagowski, J., Laier, Ch., Duka, Th., \& Brand, M. (2016). Subjective Craving for Pornography and Associative Learning Predict Tendencies Towards Cybersex Addiction in a Sample of Regular Cybersex Users. Sexual Addiction \& Compulsivity, 23(4), 342360.

Tripodi, F., Eleuteri, S., Giuliani, M., Rossi, R., Livi, S., Petruccelli, I., Petruccelli, F., Daneback, K., \& Simonelli, C. (2015). Unusual online sexual interests in heterosexual Swedish an Italian university students. Sexologies, 24(4), 8493.

United Nations Development Programme (2015). Gender Inequality Index. Available at: http://hdr.undp.org/en/ccomposite/GII (accessed May 18, 2016)

Velezmoro, R., Negy, C., \& Livia, J. (2012). Online sexual activity: cross-national comparison between United States and Peruvian college students. Archives of Sexual Behavior, 41(4), 10151025.

Weinstein, A. M., Zolek, R., Babkin, A., Cohen, K., \& Lejoyeux, M. (2015). Factors predicting cybersex use and difficulties in forming intimate relationships among male and female users of cybersex. Frontiers in Psychiatry, 6, 1-8. 
